\title{
Juvenile idiopathic arthritis-associated uveitis
}

\author{
Sarah L. N. Clarke ${ }^{1,2}$, Ethan S. Sen ${ }^{1,2^{*}}$ and Athimalaipet V. Ramanan ${ }^{1,2}$
}

\begin{abstract}
Juvenile idiopathic arthritis (JIA) is the most common rheumatic disease of childhood, with JIA-associated uveitis its most common extra-articular manifestation. JIA-associated uveitis is a potentially sight-threatening condition and thus carries a considerable risk of morbidity. The aetiology of the condition is autoimmune in nature with the predominant involvement of $\mathrm{CD}^{+} \mathrm{T}$ cells. However, the underlying pathogenic mechanisms remain unclear, particularly regarding interplay between genetic and environmental factors. JIA-associated uveitis comes in several forms, but the most common presentation is of the chronic anterior uveitis type. This condition is usually asymptomatic and thus screening for JIA-associated uveitis in at-risk patients is paramount. Early detection and treatment aims to stop inflammation and prevent the development of complications leading to visual loss, which can occur due to both active disease and burden of disease treatment. Visually disabling complications of JIA-associated uveitis include cataracts, glaucoma, band keratopathy and macular oedema. There is a growing body of evidence for the early introduction of systemic immunosuppressive therapies in order to reduce topical and systemic glucocorticoid use. This includes more traditional treatments, such as methotrexate, as well as newer biological therapies. This review highlights the epidemiology of JIA-associated uveitis, the underlying pathogenesis and how affected patients may present. The current guidelines and criteria for screening, diagnosis and monitoring are discussed along with approaches to management.
\end{abstract}

Keywords: Juvenile idiopathic arthritis, Uveitis, Epidemiology, Pathogenesis, Screening, Biologics, Prognosis

\section{Background}

JIA is the most common rheumatic disease of childhood, with JIA-associated uveitis (JIA-U) its most frequent extra-articular manifestation. Uveitis is the inflammation of the uvea (comprising the iris, choroid and retina). The Standardisation of Uveitis Nomenclature (SUN) criteria are used to define the anatomical location and time course of uveitis, allowing reproducible assessment and monitoring of disease $[1,2]$. The time course of uveitis is defined as acute, subacute, chronic or recurrent and anatomical location as anterior, intermediate, posterior or panuveitis. Additionally, JIA-U can be unilateral or bilateral, thus assessments are made of each eye in turn. JIA-U most commonly presents as chronic anterior uveitis, which is often clinically silent. This form of uveitis is most frequently associated with oligoarticular and rheumatoid factor negative polyarticular categories of JIA. In contrast, acute anterior uveitis, which is generally symptomatic, unilateral and episodic, is seen particularly in the enthesitis-related arthritis (ERA) category of JIA. Early identification and treatment of JIA-U is important given the risk of sight-threatening complications. Management of JIA-U includes the use of both topical and systemic agents and is an active area of research. Visually-disabling complications can occur both as a result of chronic disease activity and treatment burden (particularly topical glucocorticoids), and include cataracts, glaucoma, band keratopathy and macular oedema [3].

\section{Epidemiology}

Uveitis is predominantly a disease of adults, with children representing approximately 5-10\% [4]. However,

\footnotetext{
* Correspondence: ethan.sen@doctors.org.uk

${ }^{1}$ Department of Paediatric Rheumatology, Bristol Royal Hospital for Children, Upper Maudlin Street, Bristol BS2 8BJ, UK

${ }^{2}$ School of Clinical Sciences, University of Bristol, Bristol, UK
} 
the risk of delayed diagnosis and onset of complications at a young age makes this an important clinical problem. The overall incidence of uveitis in the paediatric population, reported in a study from Finland, was 4.3 per 100,000 /year and prevalence of 27.9 per 100,000 [5]. When broken down by aetiology, the prevalence of JIA-U among all causes of paediatric uveitis varies widely by referral centre, ranging from 15-67 \% across centres in Europe, North America and Israel $[4,6-9]$. The variation in these figures may partly be due to the referral cohorts from which the patients are selected, however, it should also be noted that uveitis can precede a diagnosis of arthritis in 3-7\% of children with JIA [10] and thus children presenting with uveitis need careful assessment for underlying systemic or infectious disease. When looking specifically at the prevalence of uveitis in those patients already known to have JIA, estimates of prevalence ranges from $11.6 \%$ [11] to $30 \%$ [12] although overall it appears to be decreasing over the past decade. Thus there is a well-established, reciprocal link between JIA and uveitis; uveitis is a frequent finding in JIA patients as well as JIA being a common underlying cause for the condition in children.

Regarding disease pattern, in one study where $13.1 \%$ of 1081 JIA patients developed uveitis, chronic anterior uveitis was predominant (68.3\%) [13]. However, acute anterior disease (16.2\%), recurrent anterior disease $(12 \%)$ and panuveitis (3.5\%) were also encountered.

A number of risk factors for JIA-U have been identified. These include gender, JIA category, age of onset, and ANA and HLA-B27 positivity [3, 10, 12, 14]. A younger age, female gender, oligoarticular disease and presence of ANA are risk factors for chronic anterior uveitis. In contrast, being male with HLA-B27 and ERA predispose to acute anterior uveitis. The interplay between individual risk factors is likely to be complex and inter-dependent. For example, in a retrospective study of 1047 patients with JIA, the risk of developing uveitis was age-dependent in girls, but not boys [15]. The impact of ethnicity on JIA-U is unclear. Early studies identified JIA-U in many different ethnic groups and suggested ethnicity did not play a role [16]. More recent studies have suggested that those of European descent are at increased risk of JIA-U compared to the at-risk local population [17].

\section{Pathogenesis}

Despite the well-documented link between JIA and uveitis, the reason for uveal inflammation is not well understood. It is likely that the pathophysiology of JIA-U involves both genetic and environmental elements. The genetic basis for JIA-U is likely to be complex; despite familial cases having been reported [18], monogenic or Mendelian patterns of inheritance have not been identified [19].

Most JIA-associated genes lie within the human leucocyte antigen (HLA) region, and this association supports the theory of JIA-U being an autoimmune disorder. Studies looking at the association between risk of JIA-U and HLA subtype have conflicted, however HLA alleles which confer risk have been identified when looking at HLA alleles within particular JIA categories. In patients with oligoarticular JIA, chronic anterior uveitis has been associated with the HLA-DR5 haplotype [20] and HLADRB1*1104 allele [21]. In particular the combination of HLA-DRB1*1104 and HLA-DPB1*0201 alleles is linked with a 7.7-fold increased risk of chronic uveitis. HLA-B27 is classically seen in ERA and confers an increased risk of acute anterior uveitis in this patient group [22]. HLA-DR1 is the only HLA allele which has repeatedly been shown to be protective against chronic anterior uveitis associated with JIA [23]. Additionally, there is evidence that HLA associations are temporal with HLA alleles conferring protection or susceptibility to JIA at different ages; some alleles confer protection in early children but increase risk of JIA-associated uveitis in later childhood [24].

At the cellular level, there appears to be involvement of both $\mathrm{T}$ and $\mathrm{B}$ lymphocytes in generating an immune response against native intraocular antigens including $\mathrm{S}$-arrestin (also known as retinal S-antigen), retinolbinding protein 3 , and tyrosinase-related proteins [25]. Evidence for the involvement of both $\mathrm{B}$ and $\mathrm{T}$ lymphocytes comes from immunohistochemistry of eye biopsies from patients with JIA which show a predominance of $\mathrm{CD}^{+}$rather than $\mathrm{CD}^{+}{ }^{+} \mathrm{T}$ lymphocytes as well as variable levels of $\mathrm{CD} 20^{+} \mathrm{B}$ lymphocytes. $\mathrm{CD} 4^{+}$lymphocytes include pro-inflammatory Th1 cells (producing interferon gamma) and Th17 cells (producing interleukin-17), which are regulated by both $\mathrm{CD} 4{ }^{+} \mathrm{CD} 25$ ${ }^{+} \mathrm{FoxP}^{+} \mathrm{T}$ regulatory cells (Tregs) and inducible Tregs. It is likely that autoimmunity results from imbalance between these cell subsets leading to loss of tolerance to self-antigens. In addition to the adaptive immune response, elements of the innate immune system have also been implicated in the pathogenesis of JIA-U [23].

The risk of chronic anterior uveitis in JIA patients is increased in those who are also ANA positive [26], raising the question as to whether ANAs are pathogenic in, or an epiphenomenon of, JIA-U. The specificity of the ANAs is not known although studies have previously shown higher frequency of anti- 
histone antibodies in JIA patients with uveitis compared to those with no historic or current uveitis [27, 28]. Another report, however, has not shown temporal association between anti-histone antibodies and the presence of uveitis [29]. Studies have been undertaken to address the role of ANAs by using immunofluorescence to detect antibody binding in human eyes incubated with the sera from JIA patients versus sera from healthy controls. JIA patients were shown to have increased frequency of antibodies against the iris and retina [30]. Similar findings were seen when looking at antibody binding using JIA patient (with or without uveitis) and healthy control sera in swine eyes. Walscheid et al. showed predominant binding of antibody from JIA-U patients to the iris and ciliary body [31]. Whether these antibodies are a cause or an effect of uveitis has not been elucidated by these studies, as they used sera from patients with established disease. To date, no specific intra-ocular antigen has been identified as the target for ANAs, and thus their role in pathogenesis remains unclear.

\section{Clinical features}

Uveitis can present with overt symptoms as seen in acute anterior uveitis. Typical features include eye pain, redness, headaches, photophobia and visual changes. However, chronic anterior uveitis, more commonly seen in JIA, is often completely asymptomatic. Hence, regular screening for uveitis in JIA patients is essential to detect clinically-silent, but potentially vision-threatening, disease. Even in the presence of symptoms, children may be unable to report reliably what they are experiencing, thus a need for formal assessment of vision and ocular health remains.

Sabri et al. found that the mean time from onset of JIA to onset of uveitis was 1.8 years [13]. However, uveitis can pre-date the diagnosis of JIA thus eye inflammation can go unnoticed for a significant period. Additionally, a recent study has suggested a biphasic course for the condition with a second peak of disease activity occurring around puberty [32] suggesting the need for vigilance in monitoring these patients over time.

\section{Diagnosis/Screening}

All patients at risk of JIA-U should be screened for the condition. Screening guidelines are available in several countries including the UK [33]. The UK guidelines are summarised in Box 1. The UK consensus standard is for first ophthalmological assessment to take place within 6 weeks of JIA being diagnosed or suspected [34], underlining the importance of diagnosing and treating this condition promptly.

Box 1: British Society for Paediatric and Adolescent Rheumatology/ Royal College of Ophthalmology guidelines for uveitis screening in JIA [33].

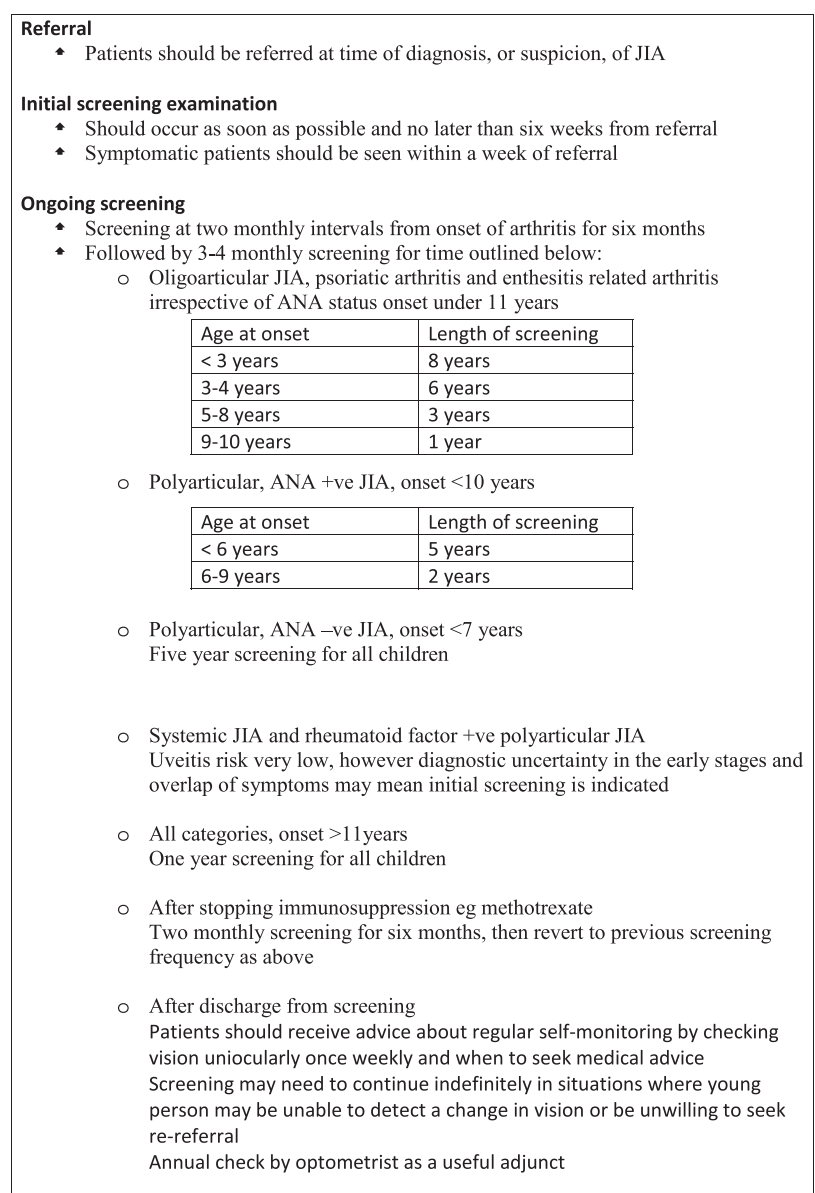

Screening of children with JIA for uveitis involves a combination of slit lamp examination, measurement of intraocular pressure and age-appropriate visual acuity (VA) testing. A slit lamp allows examination of the anterior and posterior chambers as well as the retina. A diagnosis of uveitis is made based on features of inflammation on slit lamp examination. These include cells in the anterior chamber (AC) [35] and AC flare resulting from protein leakage into the AC due to breakdown of the bloodaqueous humour barrier [36]. The SUN criteria provide a grading system for intra-ocular inflammation, which takes into account AC cells, AC flare, vitreous cells, and vitreous haze or debris (Box 2). The criteria also provide definitions of improvement and worsening of the condition (Box 2) allowing reproducible assessment and monitoring of uveitis activity. 
Box 2: Standardisation of Uveitis Nomenclature (SUN) criteria for uveitis activity [adapted with permission from Elsevier (c) Jabs et al. Am J Ophthalmol 140, 509-16 (2005)[2]]



The measurement of intra-ocular pressure is important in patients with JIA-U as patients are at risk of intraocular hypertension and glaucoma. This risk remains, despite control of active inflammation, as illustrated by one study showing the first measurement of raised intraocular pressure at a time when the disease was inactive in $60 \%$ of eyes [37]. Hence the need for regular measurement of intra-ocular pressure during follow-up.

The assessment of VA provides a measure of both disease activity and visual damage resulting from both chronic disease activity and failure or complications of treatment. There are a number of structural complications which occur in the setting of JIA-U which contribute to visual loss. These include band keratopathy, posterior synechiae, cataract, glaucoma, hypotony, macular oedema, epiretinal membrane, and optic disc oedema. The need for functional, age-appropriate assessment of vision during uveitis screening has been highlighted by Heiligenhaus et al. who have developed guidelines for measuring outcome in JIA-U and included assessment of VA as a key outcome measure [38].

\section{Treatment}

Central to the management of JIA-U is its early detection and appropriate assessment of disease activity. This requires effective communication between paediatric rheumatologists and ophthalmologists which may be helped by organisation of multi-disciplinary clinics. The aim of treatment is to achieve 0 cells in the anterior chamber (SUN AC cell grade 0) in both eyes [39]. Practical management protocols have recently been published both by our group in Bristol, UK [40] and an interdisciplinary panel from Spain [39]. A modified algorithm based on consensus guidelines [39-41] is provided in Fig. 1. Topical glucocorticoids are used in the management of acute anterior uveitis but all other treatments discussed below are in relation to chronic anterior uveitis.

Interdisciplinary guidelines on management of JIA-U advise that therapy is initiated when the AC cell grade is $>0.5+[41]$. Treatment is also indicated when there is fibrin in the AC and keratocytic precipitates with corneal oedema and loss of VA. Immunosuppressive treatment should be intensified if there is failure to see improvement in inflammation or presence of poor prognostic factors. Heiligenhaus et al. identify these factors as poor initial vision, cataract, macular oedema, dense vitreous body opacification, ocular hypotony and glaucoma. Cataract, glaucoma, synechiae and band keratopathy alone, in the absence of active uveitis, do not require antiinflammatory treatment [41].

\section{Topical glucocorticoids}

The first line treatment for both acute and chronic anterior uveitis is topical glucocorticoids [41-43]. The greatest efficacy is seen with high potency steroids such as prednisolone acetate $1 \%$ or dexamethasone phosphate $0.1 \%$ used once daily to hourly depending on the degree of inflammation [44]. Persistent treatment with frequent steroid eye drops is associated with higher incidence of cataracts. In an observational study, treatment of $\leq 3$ drops daily of topical glucocorticoid was associated with an $87 \%$ lower risk of cataracts than $>3$ drops daily (RR 0.13, $95 \%$ CI $0.02-0.69 ; p=0.02$ ) [45].

\section{Cycloplegics \\ Cycloplegics are used topically to prevent formation of synechiae by dilating the pupil in patients without syne- chiae or with grades $1-2$ (up to $180^{\circ}$ ). Options include tropicamide or cyclopentolate $0.5-1 \%$ eye drops $[39,40]$.}

\section{Systemic and regional glucocorticoids}

In severe or sight-threatening JIA-U, where rapid control of intraocular inflammation is required, systemic glucocorticoids either orally (prednisolone $1-2 \mathrm{mg} / \mathrm{kg} /$ day) or as intravenous pulse (methylprednisolone $20-30 \mathrm{mg} / \mathrm{kg}$ / day for 1-3 days) are sometimes necessary [43]. Evidence for their use derives only from adult studies [46, 47], although they are listed as options in paediatric guidelines [41]. Periocular or intraocular glucocorticoids are occasionally used for severe uveitis. The well-known side 




Fig. 1 Treatment algorithm for chronic anterior uveitis associated with juvenile idiopathic arthritis. [Adapted with permission from Springer $\odot$ Bou, R. et al. Rheumatol Int 35, 777-785 (2015) [36] and from Springer @ Heiligenhaus, A. et al. Rheumatol Int 32, 1121-1133 (2012) [38]]. At all stages aim to minimise topical steroid to $\leq 2$ drops/day while maintaining AC cell grade $\leq 0.5+.{ }^{*}$ Mycophenolate mofetil (MMF) is a potential alternative to a biologic drug if there is active uveitis but no active arthritis. Legend: AC: anterior chamber, d: days, h: hours, m: months, MTX: methotrexate, po: by mouth, sc: subcutaneous, tx: treatment, VA: visual acuity, w: weeks

effects of systemic glucocorticoids mandate weaning as soon as possible with earlier introduction of steroid-sparing immunosuppression in moderate to severe JIA-U [48].

\section{Synthetic DMARDs}

The primary indication for systemic immunosuppression with one of the DMARDs is failure of adequate control of inflammation after 3 months of topical treatment, particularly with $>3$ drops daily [41]. Recurrence of disease when topical glucocorticoids are weaned is also an indication for systemic therapy. Table 1 summarises the range of non-biological immunosuppressants used to treat JIA-U, their doses and evidence base. Evidence comes predominantly from retrospective case series since controlled clinical trials of the drugs in JIA-U have not been undertaken.

Methotrexate (MTX) remains the first second-line therapy after topical glucocorticoids. It is indicated after 12 weeks of topical treatment if there is no improvement to $\mathrm{AC}$ cell grade $\leq 0.5+$, or sooner if $>2$ drops daily are required, if there is worsening inflammation or if ocular complications develop [39, 41]. A systematic review and meta-analysis identified 9 eligible studies of methotrexate in non-infectious uveitis including 135 patients of 
Table 1 Synthetic DMARDs used in treatment of chronic anterior uveitis associated with JIA

\begin{tabular}{|c|c|c|c|c|c|}
\hline Drug name & Mechanism & Dosage and route & Common side effects & Evidence & Key references \\
\hline Methotrexate & $\begin{array}{l}\text { Cellular adenosine } \\
\text { release [95] }\end{array}$ & $\begin{array}{l}10-15 \mathrm{mg} / \mathrm{m}^{2} \\
\text { (or } 0.3-0.6 \mathrm{mg} / \mathrm{kg} \text { ) } \\
\text { po or sc once weekly }\end{array}$ & $\begin{array}{l}\text { Gl discomfort, nausea, } \\
\text { elevated liver enzymes }\end{array}$ & $\begin{array}{l}\text { Systematic review and } \\
\text { meta-analysis of retrospective } \\
\text { case series ( } n=135) \text { : } \\
\text { improvement in } 73 \%\end{array}$ & [49] \\
\hline Azathioprine & $\begin{array}{l}\text { Purine nucleoside } \\
\text { analogue, inhibits } \\
\text { DNA replication }\end{array}$ & $\begin{array}{l}1 \mathrm{mg} / \mathrm{kg} \text { od, } \\
\text { increasing to } \\
\text { maximum } \\
3 \mathrm{mg} / \mathrm{kg} \text { od }\end{array}$ & $\begin{array}{l}\text { Gl discomfort, bone } \\
\text { marrow suppression, } \\
\text { liver impairment }\end{array}$ & $\begin{array}{l}\text { Retrospective case series } \\
(n=41) \text { : uveitis inactivity in } \\
61.5 \% \text { as initial monotherapy; } \\
66.7 \% \text { as combination therapy }\end{array}$ & {$[96]$} \\
\hline $\begin{array}{l}\text { Mycophenolate } \\
\text { mofetil }\end{array}$ & $\begin{array}{l}\text { Inhibitor of inosine-5- } \\
\text { monophosphate } \\
\text { dehydrogenase }\end{array}$ & $\begin{array}{l}300 \mathrm{mg} / \mathrm{m}^{2} \mathrm{bd} \\
\text { increasing to } \\
600 \mathrm{mg} / \mathrm{m}^{2} \text { bd }\end{array}$ & $\begin{array}{l}\text { Gl discomfort, leukopenia, } \\
\text { hair loss }\end{array}$ & $\begin{array}{l}\text { Several retrospective case series } \\
(n=17,52 \text { and } 85 ; \text { not all with } \\
\text { JIA, variable outcome measures): } \\
\text { response in } 55-88 \%\end{array}$ & [97-99] \\
\hline Ciclosporin & $\begin{array}{l}\text { Calcineurin inhibitor } \\
\text { blocking } T \text { cell } \\
\text { proliferation }\end{array}$ & $\begin{array}{l}2.5-5 \mathrm{mg} / \mathrm{kg} / \text { day } \\
\text { in } 2 \text { doses }\end{array}$ & $\begin{array}{l}\text { Gl disturbance, hypertension, } \\
\text { renal and liver dysfunction, } \\
\text { lipid abnormalities }\end{array}$ & $\begin{array}{l}\text { Retrospective case series } \\
(n=82 \text { and } 14) \text { : uveitis inactivity } \\
\text { in } 24 \% \text { as monotherapy, } \\
48.6 \% \text { as combination therapy }\end{array}$ & {$[100,101]$} \\
\hline Tacrolimus & $\begin{array}{l}\text { Calcineurin inhibitor } \\
\text { blocking } T \text { cell } \\
\text { proliferation }\end{array}$ & $\begin{array}{l}50-150 \text { microgram/ } \\
\mathrm{kg} \text { bd }\end{array}$ & $\begin{array}{l}\text { Gl disturbance, hypertension, } \\
\text { renal and liver dysfunction, } \\
\text { lipid abnormalities, blood } \\
\text { disorders }\end{array}$ & $\begin{array}{l}\text { Retrospective case series ( } n=62 \text {, } \\
\text { mostly adults with idiopathic uveitis): } \\
\text { permitted glucocorticoid tapering } \\
\text { and improved visual acuity }\end{array}$ & [102] \\
\hline
\end{tabular}

Legend: $b d$ twice daily, Gl gastro-intestinal, od once daily, po by mouth, sc subcutaneous

whom 121 had JIA [49]. The dose of $15 \mathrm{mg} / \mathrm{m}^{2}$ once weekly was most commonly used, with a maximum of $20 \mathrm{mg}$ orally or $25 \mathrm{mg}$ by subcutaneous injection [50]. The mean time to MTX-induced remission was reported as 4.25 months with duration of remission of 10.3 months [50]. In the systematic review, improvements in intraocular inflammation were seen in $73 \%$ (95\% CI 67-81\%). Adverse events, most commonly gastrointestinal discomfort, nausea and elevated liver enzymes, were experienced in $19.6 \%$ of patients where data were available [49]. MTX treatment was associated with a reduced need for cataract extraction, required in $29 \%$ of treated patients compared with $64 \%$ of those never receiving MTX [51].

One study has reported on uveitis relapse after withdrawal of MTX. Among 22 patients with JIA-U who were treated with MTX, the drug was discontinued in $59 \%$ because of inactive disease after a mean of 1.5 years of inactivity and a total 3.1 years duration of therapy [52]. Factors associated with significantly longer relapsefree survival were: treatment $>3$ years, age $>8$ years when MTX was withdrawn, and inactivity of uveitis for longer than 2 years before withdrawal. One year increase in duration of inactive uveitis before withdrawal of MTX was associated with a decreased hazard of relapse of $93 \%$. It is recommended that MTX is continued for at least 12 months once uveitis is inactive and for 24 months in those with poor visual prognosis [39].

Other DMARDs such as mycophenolate mofetil (MMF), tacrolimus, azathioprine, and ciclosporin are used less frequently in treatment of JIA-U [43, 53, 54]. Their use is detailed in Table 1. Leflunomide, which is occasionally used to treat joint disease in JIA, has been associated with more frequent uveitis flares compared with MTX in one retrospective study [55]. Combinations of two DMARDs (such as MTX and MMF) have been tried in more resistant cases. However, we have previously reported that addition of a third immunosuppressive agent has limited efficacy and is associated with increased risk of infections [56]. Current treatment algorithms recommend that if there is worsening disease or failure to achieve AC cell grade 0 after 3-4 months on MTX, then a biologic drug is added [39, 57].

\section{Biologic drugs}

Over the past decade, randomised controlled trials (RCTs) of biologic agents have demonstrated their efficacy in controlling joint disease in JIA [58]. The same drugs have also been used in treatment of associated uveitis (Table 2). The greatest evidence, thus far derived from cohort studies and with RCTs underway, supports the use of adalimumab in treatment of JIA-U. A doubleblind, placebo-controlled RCT of adalimumab was stopped early due to efficacy after randomising 90 patients [59]. Analysis of the primary endpoint ("time to treatment failure") showed a positive effect in favour of adalimumab with a hazard ratio of 0.27 (95\% CI $0.13-$ $0.52, p<0.0001)$. Adverse events were noted in $88.3 \%$ of patients on adalimumab and $90 \%$ on placebo, with infections being the most common serious adverse event in the treatment group.

In contrast to adalimumab, a double-blind RCT of etanercept in 12 patients with JIA-U showed no difference between the drug and placebo [60]. With this small number of patients, the study was powered to detect a difference only if greater than 70 percentage points between treatment arms. Etanercept is not recommended 
Table 2 Biological immunosuppressants used in treatment of chronic anterior uveitis associated with JIA

\begin{tabular}{|c|c|c|c|c|c|}
\hline Target & Drug name & Drug class & Dosage and route & Evidence & Key references \\
\hline \multirow[t]{5}{*}{ TNFa } & Etanercept & Dimeric fusion protein & $\begin{array}{l}\text { Not recommended for treatment } \\
\text { of JIA-U }\end{array}$ & $\begin{array}{l}\text { RCT: no more effective than placebo. } \\
\text { Case reports of new uveitis on } \\
\text { etanercept }\end{array}$ & {$[60,61]$} \\
\hline & Infliximab & $\begin{array}{l}\text { Chimeric (mouse-human) } \\
\mathrm{mAb}\end{array}$ & $\begin{array}{l}6 \mathrm{mg} / \mathrm{kg} \text { IV initially, then } 3-10 \mathrm{mg} / \mathrm{kg} \text {. } \\
2^{\text {nd }} \text { dose at } 2 \text { weeks, then every } \\
4-8 \text { weeks depending on response }\end{array}$ & Several case series showing efficacy & {$[61]$} \\
\hline & \multirow[t]{2}{*}{ Adalimumab } & \multirow[t]{2}{*}{ Fully human $\mathrm{mAb}$} & $24 \mathrm{mg} / \mathrm{m}^{2} \mathrm{sc} \mathrm{q} 2 \mathrm{w}$ & \multirow{2}{*}{$\begin{array}{l}\text { Several case series showing efficacy. } \\
\text { RCTs in progress }\end{array}$} & \multirow[t]{2}{*}[61,90]{} \\
\hline & & & $\begin{array}{l}\text { In practice often } 20 \text { mg sc q2w } \\
\text { (body weight }<30 \mathrm{~kg} \text { ), } 40 \mathrm{mg} \text { sc q2w } \\
\text { (body weight } \geq 30 \mathrm{~kg} \text { ) }\end{array}$ & & \\
\hline & Golimumab & Fully human mAb & $50 \mathrm{mg} \mathrm{sc} \mathrm{q4w}$ & Case series $(n=3)$ showing efficacy & [103] \\
\hline IL-6 & Tocilizumab & Humanised mAb & $\begin{array}{l}10 \mathrm{mg} / \mathrm{kg} \text { (body weight }<30 \mathrm{~kg} \text { ), } \\
8 \mathrm{mg} / \mathrm{kg} \text { (body weight }>30 \mathrm{~kg} \text { ) } \\
\mathrm{IV} \mathrm{q} 4 \mathrm{w}\end{array}$ & $\begin{array}{l}\text { Case series }(n=3) \text { and case report } \\
\text { showing efficacy. Phase II trial in } \\
\text { progress }\end{array}$ & {$[92,93,104,105]$} \\
\hline $\begin{array}{l}\text { CD80/86 } \\
\text { (CTLA4) }\end{array}$ & Abatacept & Fully human fusion protein & $\begin{array}{l}10 \mathrm{mg} / \mathrm{kg} \text { IV at weeks } 0,2,4 \\
\text { then } \mathrm{q} 4 \mathrm{w}\end{array}$ & $\begin{array}{l}\text { Case series ( } n=7 \text { and } n=2) \text { showing } \\
\text { efficacy. Lack of sustained response } \\
\text { in severe uveitis }(n=21)\end{array}$ & {$[94,106-108]$} \\
\hline $\mathrm{CD} 20$ & Rituximab & $\begin{array}{l}\text { Chimeric (mouse-human) } \\
\mathrm{mAb}\end{array}$ & $\begin{array}{l}375 \mathrm{mg} / \mathrm{m}^{2} \text { or } 750 \mathrm{mg} / \mathrm{m}^{2} \mathrm{IV} \\
\text { two doses } 2 \text { weeks apart }\end{array}$ & $\begin{array}{l}\text { Case series ( } n=10 \text { and } n=8 \text { with } \\
\text { long-term follow-up) showing } \\
\text { efficacy in most patients }\end{array}$ & [109-111] \\
\hline
\end{tabular}

Legend: CTLA-4 cytotoxic T-lymphocyte-associated antigen 4, IL interleukin, $I V$ intravenous, JA- $U$ juvenile idiopathic arthritis-associated uveitis, mAb monoclonal antibody, od once daily, ow once per week, $q 2 w$ every 2 weeks, $q 4 w$ every 4 weeks, RCT randomised controlled trial, sc subcutaneous, TNF tumour necrosis factor

in patients with JIA-U. A meta-analysis including 229 children with JIA-U has shown that infliximab and adalimumab have similar efficacy and both are superior to etanercept [61]. However, during 40 months' follow-up, uveitis more commonly remained in remission in those treated with adalimumab compared with infliximab (60\% vs $18.8 \%$ respectively) [62]. A small case series has reported that switching between anti-TNF agents, particularly from infliximab to adalimumab, can regain control of uveitis [63]. There have been no systematic studies of treatment options after failure of an anti-TNF although other biologics are sometimes used. Experience using abatacept, tocilizumab and rituximab for treatment of JIA-U has been reported in case series (Table 2). Efficacy was seen in most patients although only small numbers have been reported.

The duration of maintenance therapy on biologic agents is not certain although consensus recommendations suggest continuing treatment for 24 months of inactive disease [39]. One retrospective cohort study $(n=50,44 \%$ with JIA) has reported on uveitis reactivation after stopping infliximab $(n=45)$ or adalimumab $(n=5)$ [64]. Of 19 patients who achieved remission and were subsequently withdrawn from anti-TNFs, $63.8 \%$ had reactivation within 12 months and there did not appear to be an association with duration of medication-induced remission.

There are increasing data on the safety of biologic drugs in JIA and rates of adverse events such as uveitis. Several studies have reported flares or new-onset uveitis while on etanercept [65-67]. Evidence from national registries suggests that etanercept is associated with a greater number of uveitis cases than adalimumab or infliximab [68]. However, no definite causative effect of etanercept can be proved from these retrospective observational studies and the prescribing pattern of the different anti-TNFs may be a confounding factor [69]. A German registry study ( $n=3467$ patients) suggested that in those patients with a known negative past history of uveitis the rate of a new uveitis event was $3.2 / 1000$ patient years (PY) in the MTX group, 1.9/1000PY in the etanercept monotherapy group and $0.9 / 1000 \mathrm{PY}$ in the group on the combination of both [70]. An observational study reporting adverse events in JIA patients receiving biologics in Finland ( $n=348$ patients) reported a rate of new-onset uveitis of $0.8 / 100 \mathrm{PY}, 0.3 / 100 \mathrm{PY}$ and $0.5 / 100 \mathrm{PY}$ while on etanercept, infliximab and adalimumab respectively [71]. The rates of uveitis flare were 2.8/100PY, 8.0/100PY and 3.8/100PY for each respective treatment. The authors suggest that the apparently higher rate of flare while on infliximab is because most patients with a pre-existing diagnosis of uveitis were started on this drug during the observation period (1999-2009).

\section{Surgical treatments}

Several complications of uveitis, such as cataracts and glaucoma, may require surgical treatment. Removal of the lens by phacoemulsification is the usual surgical treatment for a cataract that is impacting significantly on visual acuity [72]. Complete control of intraocular inflammation for at least 3 months prior to surgery is associated with improved outcomes [73, 74]. Aggressive 
courses of pre- and post-operative topical and systemic glucocorticoids may be required to optimise surgical results [40]. Surgical treatment may also be required for glaucoma associated with JIA-U unresponsive to pharmacological management. Interventional options include goniotomy, insertion of a glaucoma drainage device or trabeculectomy [75-77].

\section{Prognosis}

Chronic anterior uveitis associated with JIA is a sightthreatening disease with ocular complications resulting from both the disease itself and its treatments. Visual loss may be present at first assessment with one study describing VA of $20 / 50$ or worse in $40.3 \%$ and $20 / 200$ or worse in $24.2 \%$ at presentation [78]. A systematic literature review looking at outcomes in JIA-U showed an adverse visual outcome (VA $<20 / 40$ both eyes together) in $9.2 \%$ of those with uveitis [3]. The main complications were cataracts, glaucoma and band keratopathy occurring in 20.5, 18.9 and $15.7 \%$ respectively.

Several studies have looked at long-term follow-up. Skarin et al. reported a cohort of 55 JIA-U patients between 1973 and 1982 [79]. Seven years after uveitis onset, $42 \%$ had cataracts and $5 \%$ glaucoma. At 24 years, $51 \%$ had cataracts, $22 \%$ glaucoma and $49 \%$ had signs of active uveitis or were receiving topical glucocorticoids for recent flares. Similar persistence into adulthood of asymptomatic uveitis in almost half of patients with JIA-U was seen in a cohort of 19 subjects who were born in 1976-1980 [80].

Several factors have been identified which are associated with a more severe course of uveitis and development of complications [81-83]. These risk factors for poor prognosis include: male gender; young age at onset of uveitis; short duration between onset of arthritis and development of uveitis; and presence of synechiae at first diagnosis of uveitis. A retrospective case series including 65 children with JIA-U showed significantly worse VA in boys versus girls at 1 year and 3 year follow-up [84]. Another study suggested that a shorter time interval between arthritis and uveitis onset is the main predictor of severity of uveitis [85]. Risk factors for visual loss, a key long-term outcome, were examined in a retrospective study with 596 affected eyes [78]. The overall incidence of visual loss to $20 / 50$ or worse was 0.18 /eye year (EY). The overall rate of developing a new ocular complication was $0.15 / \mathrm{EY}$ but significantly lower at $0.04 / \mathrm{EY}$ in those with no complications at baseline. The same study also showed bilateral uveitis, active uveitis ( $\geq 1+\mathrm{AC}$ cells or $\geq 0.5$ vitreous haze), longer duration of uveitis, presence of posterior synechiae, abnormal intraocular pressure (IOP) and history of prior intraocular surgery were associated with worse vision during follow-up.
There are suggestions that both JIA-U prevalence and frequency of complications may be decreasing over time. A prospective, cross-sectional study from Germany including 18,555 JIA patients between 2002 and 2013 found a significant decrease in uveitis prevalence from 13.0 to $11.6 \%$ [86]. There were also significant decreases in uveitis complications from 33.6 to $23.9 \%$ (OR 0.94, $p<0.001)$. Over the same time period there were increases in use of synthetic DMARDs (39.8 to $47.2 \%$ ) and biologic DMARDs (3.3 to $21.8 \%$ ). Another study compared a cohort of patients with JIA-U from 1990$1993(n=239)$ with a 2000-2003 cohort $(n=240)$ and found a frequency of complications of 35 and $21 \%$ respectively [87]. This apparent reduction may be related to earlier use of systemic immunosuppression, such as methotrexate, to treat joint disease. Evidence to support this comes from a subgroup $(n=3512)$ of the German 2002-2013 JIA cohort with disease duration $<12$ months at first documentation and more than 2 years of follow-up [88]. Compared to those with no DMARD treatment in the year before uveitis onset, the risk of uveitis was significantly decreased by methotrexate (hazard ratio [HR] 0.63 , $p=0.022$ ), by TNF inhibitors (HR $0.56, p=0.001$ ) and by a combination of the two (HR 0.10, $p=0.001$ ). The use of methotrexate early, specifically within the first year of JIA, was associated with a clearly reduced risk of uveitis compared with no early methotrexate $(4.8 \%$ vs $8.5 \%$ respectively; HR $0.29, p<0.001$ ).

\section{Future directions}

Better understanding of the pathogenesis of JIA-U may help to identify biomarkers, either genetic or perhaps plasma factors, which would allow stratification of patients to higher risk groups. These could be targeted with earlier and more aggressive therapy.

Key to improvement of therapies is the effective translation from bench to bedside [89]. High quality evidence for efficacy and safety of novel treatments specifically within a JIA-U population is required. The SYCAMORE study, a randomised placebo-controlled multicentre trial of adalimumab for JIA-U has completed recruitment and is now in follow-up [59, 90]. Another RCT of adalimumab is awaiting report from France [91]. The APTITUDE trial, an open-label study of subcutaneous tocilizumab for anti-TNF-refractory JIA-U is recruiting patients in the UK [92]. There are also smaller studies underway or planned examining tocilizumab and abatacept in JIA-U $[93,94]$.

\section{Conclusion}

JIA-associated uveitis is the commonest extra-articular manifestation of JIA with significant numbers of children still developing sight-threatening complications. Close co-operation between paediatric rheumatologists and 
ophthalmologists and regular screening with slit lamp examination is essential for early diagnosis. Growing evidence supports the early use of systemic immunosuppression with the aim of quiescence of intraocular inflammation and avoidance of steroid-related side effects. A range of biologic drugs are being used, mostly on the basis of retrospective observational cohort studies, in methotrexate-resistant or intolerant cases. Prospective trials of adalimumab and tocilizumab which are now underway will provide further evidence about their efficacy and safety in treatment of JIA-U. A better understanding of the immunopathogenesis and identification of predictive biomarkers to target the widening therapeutic armamentarium will be a key goal in the years to come.

\begin{abstract}
Abbreviations
AC: anterior chamber; ANA: antinuclear antibody; DMARD: disease-modifying anti-rheumatic drug; EY: eye year; HLA: human leucocyte antigen; JIA: juvenile idiopathic arthritis; JIA-U: juvenile idiopathic arthritis-associated uveitis; MMF: mycophenolate mofetil; MTX: methotrexate; PY: patient year; RCT: randomised controlled trial; SUN: Standardisation of Uveitis Nomenclature; TNF: tumour necrosis factor; Treg: T regulatory cell; VA: visual acuity.
\end{abstract}

\section{Competing interests}

SLNC declares no competing interests. ESS has received sponsorship to attend meetings from Abbvie. AVR has received honoraria/speaker fees from Pfizer, Abbvie, Roche, Novartis and SOBI pharmaceuticals and is co-chief investigator of the SYCAMORE and APTITUDE studies. The authors have received no funding in respect of this article.

\section{Authors' contributions}

SLNC and ESS researched data and wrote the article. AVR made significant contributions to discussion of content and review/editing of the article prior to submission. All authors read and approved the final manuscript.

\section{Authors' information \\ SLNC (BSC, BM BCh, MRCPCH) received her BSC in Immunology from the University of Bristol, UK, prior to obtaining her medical degree at the University of Oxford, UK, in 2011. She is a National Institute for Health Research (NIHR) funded Academic Clinical Fellow in Paediatric Rheumatology at Bristol Royal Hospital for Children. Her research interest is in JIA-associated uveitis and paediatric immunophenotyping. \\ ESS (BA, BM BCh, MRCPCH, FHEA) qualified from the University of Oxford, UK, in 2004. He is a specialty trainee in Paediatric Rheumatology at Bristol Royal Hospital for Children and was previously awarded a Barbara Ansell Fellowship in Paediatric Rheumatology by Arthritis Research UK. He is currently a National Institute for Health Research (NIHR) Rare Disease Translational Research Collaboration (RD-TRC) Clinical Research Fellow at the University of Bristol. He has research interests in SLE/lupus nephritis and steroid-resistant nephrotic syndrome. \\ AVR is Lead Consultant at Bristol Royal Hospital for Children and Professor of Rheumatology at University of Bristol. He is scientific member of Arthritis Research UK Paediatric Rheumatology Clinical Studies Group and Associate Director of ARUK funded Paediatric Experimental Arthritis Treatment Centre based in Liverpool.}

\section{Acknowledgements}

SLNC is an Academic Clinical Fellow funded by the National Institute for Health Research (NIHR). ESS is funded by an NIHR Rare Disease Translational Research Collaboration (RD-TRC) Clinical Research Fellowship. The views expressed are those of the authors and not necessarily those of the NHS, the $\mathrm{NIHR}$ or the Department of Health. Some of the text and tables in this article have been adapted from Sen ES, Dick AD \& Ramanan AV [Nature Rev Rheumatol. 2015;11:338-48].

Received: 29 January 2016 Accepted: 21 April 2016 Published online: 27 April 2016

\section{References}

1. Deschenes J, Murray PI, Rao NA, Nussenblatt RB, International Uveitis Study Group. International Uveitis Study Group (IUSG): clinical classification of uveitis. Ocul Immunol Inflamm. 2008;16(1):1-2.

2. Jabs DA, Nussenblatt RB, Rosenbaum JT, Standardization of Uveitis Nomenclature (SUN) Working Group. Standardization of uveitis nomenclature for reporting clinical data. Results of the First International Workshop. Am J Ophthalmol. 2005;140(3):509-16.

3. Carvounis PE, Herman DC, Cha S, Burke JP. Incidence and outcomes of uveitis in juvenile rheumatoid arthritis, a synthesis of the literature. Graefes Arch Clin Exp Ophthalmol. 2006;244(3):281-90.

4. Edelsten C, Reddy MA, Stanford MR, Graham EM. Visual loss associated with pediatric uveitis in english primary and referral centers. Am J Ophthalmol. 2003;135(5):676-80.

5. Paivonsalo-Hietanen T, Tuominen J, Saari KM. Uveitis in children: population-based study in Finland. Acta Ophthalmol Scand. 2000;78(1):84-8.

6. de Boer J, Wulffraat N, Rothova A. Visual loss in uveitis of childhood. Br J Ophthalmol. 2003;87(7):879-84.

7. Holland GN, Stiehm ER. Special considerations in the evaluation and management of uveitis in children. Am J Ophthalmol. 2003;135(6):867-78.

8. BenEzra D, Cohen E, Maftzir G. Uveitis in children and adolescents. Br J Ophthalmol. 2005;89(4):444-8.

9. Kump LI, Cervantes-Castañeda RA, Androudi SN, Foster CS. Analysis of pediatric uveitis cases at a tertiary referral center. Ophthalmology. 2005;112(7):1287-92

10. Heiligenhaus A, Heinz C, Edelsten C, Kotaniemi K, Minden K. Review for disease of the year: epidemiology of juvenile idiopathic arthritis and its associated uveitis: the probable risk factors. Ocul Immunol Inflamm. 2013;21(3):180-91.

11. Angeles-Han ST, Pelajo CF, Vogler LB, Rouster-Stevens K, Kennedy C, Ponder L, et al. Risk markers of juvenile idiopathic arthritis-associated uveitis in the Childhood Arthritis and Rheumatology Research Alliance (CARRA) Registry. J Rheumatol. 2013;40(12):2088-96.

12. Moradi A, Amin RM, Thorne JE. The role of gender in juvenile idiopathic arthritis-associated uveitis. J Ophthalmol. 2014;2014:461078.

13. Sabri K, Saurenmann RK, Silverman ED, Levin AV. Course, complications, and outcome of juvenile arthritis-related uveitis. J AAPOS. 2008;12(6):539-45.

14. Qian Y, Acharya NR. Juvenile idiopathic arthritis-associated uveitis. Curr Opin Ophthalmol. 2010;21(6):468-72.

15. Saurenmann RK, Levin AV, Feldman BM, Laxer RM, Schneider R, Silverman ED. Risk factors for development of uveitis differ between girls and boys with juvenile idiopathic arthritis. Arthritis Rheum. 2010;62(6):1824-8.

16. Rosenberg AM. Uveitis associated with juvenile rheumatoid arthritis. Semin Arthritis Rheum. 1987;16(3):158-73.

17. Saurenmann RK, Rose JB, Tyrrell P, Feldman BM, Laxer RM, Schneider R, et al. Epidemiology of juvenile idiopathic arthritis in a multiethnic cohort: ethnicity as a risk factor. Arthritis Rheum. 2007;56(6):1974-84.

18. Julián K, Terrada C, Quartier P, Lehoang P, Bodaghi B. Uveitis related to juvenile idiopathic arthritis: familial cases and possible genetic implication in the pathogenesis. Ocul Immunol Inflamm. 2010;18(3):172-7.

19. Vastert SJ, Bhat P, Goldstein DA. Pathophysiology of JIA-associated uveitis. Ocul Immunol Inflamm. 2014;22(5):414-23.

20. Giannini EH, Malagon CN, Van Kerckhove C, Taylor J, Lovell DJ, Levinson JE, et al. Longitudinal analysis of HLA associated risks for iridocyclitis in juvenile rheumatoid arthritis. J Rheumatol. 1991;18(9):1394-7.

21. Melin-Aldana H, Giannini EH, Taylor J, Lovell DJ, Levinson JE, Passo MH, et al. Human leukocyte antigen-DRB1*1104 in the chronic iridocyclitis of pauciarticular juvenile rheumatoid arthritis. J Pediatr. 1992;121(1):56-60.

22. Du L, Kijlstra A, Yang P. Immune response genes in uveitis. Ocul Immunol Inflamm. 2009;17(4):249-56.

23. Kalinina Ayuso V, Makhotkina N, van Tent-Hoeve M, de Groot-Mijnes JDF, Wulffraat NM, Rothova A, et al. Pathogenesis of juvenile idiopathic arthritis associated uveitis: the known and unknown. Surv Ophthalmol. 2014:59(5):517-31.

24. Murray KJ, Moroldo MB, Donnelly P, Prahalad S, Passo MH, Giannini EH, et al. Age-specific effects of juvenile rheumatoid arthritis-associated HLA alleles. Arthritis Rheum. 1999:42(9):1843-53.

25. Lee RW, Dick AD. Current concepts and future directions in the pathogenesis and treatment of non-infectious intraocular inflammation. Eye (Lond). 2012;26(1):17-28. 
26. Saurenmann RK, Levin AV, Feldman BM, Rose JB, Laxer RM, Schneider R, et al. Prevalence, risk factors, and outcome of uveitis in juvenile idiopathic arthritis: a long-term followup study. Arthritis Rheum. 2007;56(2):647-57.

27. Nordal EB, Songstad NT, Berntson L, Moen T, Straume B, Rygg M. Biomarkers of chronic uveitis in juvenile idiopathic arthritis: predictive value of antihistone antibodies and antinuclear antibodies. J Rheumatol. 2009;36(8):1737-43.

28. Monestier M, Losman JA, Fasy TM, Debbas ME, Massa M, Albani S, et al. Antihistone antibodies in antinuclear antibody-positive juvenile arthritis. Arthritis Rheum. 1990:33(12):1836-41.

29. Massa M, De Benedetti F, Pignatti P, Albani S, Monestier M, Martini A. Lack of temporal association of iridocyclitis with IgG reactivities to core histones and nucleosome subparticles in pauciarticular juvenile chronic arthritis. Br J Rheumatol. 1995;34(6):507-11.

30. Uchiyama RC, Osborn TG, Moore TL. Antibodies to iris and retina detected in sera from patients with juvenile rheumatoid arthritis with iridocyclitis by indirect immunofluorescence studies on human eye tissue. J Rheumatol. 1989;16(8):1074-8

31. Walscheid K, Hennig M, Heinz C, Wasmuth S, Busch M, Bauer D, et al. Correlation between disease severity and presence of ocular autoantibodies in juvenile idiopathic arthritis-associated uveitis. Invest Ophthalmol Vis Sci. 2014;55(6):3447-53.

32. Hoeve M, Kalinina Ayuso V, Schalij-Delfos NE, Los LI, Rothova A, de Boer JH. The clinical course of juvenile idiopathic arthritis-associated uveitis in childhood and puberty. Br J Ophthalmol. 2012;96(6):852-6.

33. British Society for Paediatric and Adolescent Rheumatology, Royal College of Ophthalmology. Guidelines for screening for Uveitis in Juvenile idiopathic arthritis. 2006. http://www.bspar.org.uk/DocStore/FileLibrary/PDFs/BSPAR\% 20Guidelines\%20for\%20Eye\%20Screening\%202006.pdf Accessed 4 Jan 2016

34. Davies K, Cleary G, Foster H, Hutchinson E, Baildam E, British Society of Paediatric and Adolescent Rheumatology. BSPAR standards of care for children and young people with juvenile idiopathic arthritis. Rheumatology. 2010;49(7):1406-8.

35. Sen ES, Dick AD, Ramanan AV. Uveitis associated with juvenile idiopathic arthritis. Nat Rev Rheumatol. 2015;11(6):338-48.

36. Tappeiner C, Heinz C, Roesel M, Heiligenhaus A. Elevated laser flare values correlate with complicated course of anterior uveitis in patients with juvenile idiopathic arthritis. Acta Ophthalmol. 2011;89(6):e521-7.

37. Heinz C, Schumacher C, Roesel M, Heiligenhaus A. Elevated intraocular pressure in uveitis associated with juvenile idiopathic arthritis-associated uveitis, often detected after achieving inactivity. $\mathrm{Br} J$ Ophthalmol. 2012;96(1):140-1.

38. Heiligenhaus A, Foeldvari I, Edelsten C, Smith JR, Saurenmann RK Bodaghi B, et al. Proposed outcome measures for prospective clinical trials in juvenile idiopathic arthritis-associated uveitis: a consensus effort from the multinational interdisciplinary working group for uveitis in childhood. Arthritis Care Res. 2012;64(9):1365-72.

39. Bou R, Adan A, Borras F, Bravo B, Calvo I, De Inocencio J, et al. Clinical management algorithm of uveitis associated with juvenile idiopathic arthritis: interdisciplinary panel consensus. Rheumatol Int 2015;35(5):777-85.

40. Hawkins MJ, Dick AD, Lee RJ, Ramanan AV, Carreño E, Guly CM, et al. Managing juvenile idiopathic arthritis-associated uveitis. Surv Ophthalmol. 2015. doi:10.1016/j.survophthal.2015.10.005.

41. Heiligenhaus A, Michels H, Schumacher C, Kopp I, Neudorf U, Niehues T, et al. Evidence-based, interdisciplinary guidelines for anti-inflammatory treatment of uveitis associated with juvenile idiopathic arthritis. Rheumatol Int. 2012;32(5):1121-33.

42. Bou R, Iglesias E, Antón J. Treatment of uveitis associated with juvenile idiopathic arthritis. Curr Rheumatol Rep. 2014;16(8):437.

43. Simonini G, Cantarini L, Bresci C, Lorusso M, Galeazzi M, Cimaz R. Current therapeutic approaches to autoimmune chronic uveitis in children. Autoimmun Rev. 2010;9(10):674-83.

44. Foster CS, Alter G, DeBarge LR, Raizman MB, Crabb JL, Santos Cl, et al. Efficacy and safety of rimexolone $1 \%$ ophthalmic suspension vs $1 \%$ prednisolone acetate in the treatment of uveitis. Am J Ophthalmol. 1996;122(2):171-82.

45. Thorne JE, Woreta FA, Dunn JP, Jabs DA. Risk of cataract development among children with juvenile idiopathic arthritis-related uveitis treated with topical corticosteroids. Ophthalmology. 2010;117(7):1436-41.
46. Wakefield D, McCluskey P, Penny R. Intravenous pulse methylprednisolone therapy in severe inflammatory eye disease. Arch Ophthalmol. 1986;104(6):847-51.

47. Charkoudian LD, Ying GS, Pujari SS, Gangaputra S, Thorne JE, Foster CS, et al. High-dose intravenous corticosteroids for ocular inflammatory diseases. Ocul Immunol Inflamm. 2012;20(2):91-9.

48. Ramanan AV, Dick AD. Blinded by lack of evidence. Rheumatology. 2013;52(5):765-6.

49. Simonini G, Paudyal P, Jones GT, Cimaz R, Macfarlane GJ. Current evidence of methotrexate efficacy in childhood chronic uveitis: a systematic review and meta-analysis approach. Rheumatology. 2013;52(5):825-31.

50. Foeldvari I, Wierk A. Methotrexate is an effective treatment for chronic uveitis associated with juvenile idiopathic arthritis. J Rheumatol. 2005;32(2):362-5.

51. Sijssens KM, Rothova A, Van De Vijver DA, Stilma JS, De Boer JH. Risk factors for the development of cataract requiring surgery in uveitis associated with juvenile idiopathic arthritis. Am J Ophthalmol. 2007;144(4):574-9.

52. Kalinina Ayuso V, van de Winkel EL, Rothova A, de Boer JH. Relapse rate of uveitis post-methotrexate treatment in juvenile idiopathic arthritis. Am J Ophthalmol. 2011;151(2):217-22.

53. Sharma SM, Dick AD, Ramanan AV. Non-infectious pediatric uveitis: an update on immunomodulatory management. Paediatr Drugs. 2009;11(4):229-41.

54. Amin RM, Miserocchi E, Thorne JE, Hornbeak D, Jabs DA, Zierhut M. Treatment options for juvenile idiopathic arthritis (JIA) associated uveitis. Ocul Immunol Inflamm. 2015;1-10.

55. Bichler J, Benseler SM, Krumrey-Langkammerer M, Haas JP, Hugle B. Leflunomide is associated with a higher flare rate compared to methotrexate in the treatment of chronic uveitis in juvenile idiopathic arthritis. Scand J Rheumatol. 2015:44(4):280-3.

56. Little JA, Sen ES, Strike H, Hinchcliffe A, Guly CM, Lee RW, et al. The safety and efficacy of noncorticosteroid triple immunosuppressive therapy in the treatment of refractory chronic noninfectious uveitis in childhood. J Rheumatol. 2014;41(1):136-9.

57. Heiligenhaus A, Minden K, Foll D, Pleyer U. Uveitis in juvenile idiopathic arthritis. Dtsch Arztebl Int. 2015;112(6):92-100. i.

58. Sen ES, Ramanan AV. New age of biological therapies in paediatric rheumatology. Arch Dis Child. 2014;99(7):679-85.

59. Ramanan AV, Dick AD, McKay A, Jones A, Williamson P, Compeyrot-Lacassagne $S$, et al. A randomised controlled trial of the clinical effectiveness, safety and cost-effectiveness of adalimumab in combination with Methotrexate for the treatment of juvenile idiopathic arthritis associated uveitis [abstract]. Arthritis Rheumatol. 2015;67 Suppl 10:3931-3.

60. Smith JA, Thompson DJ, Whitcup SM, Suhler E, Clarke G, Smith S, et al. A randomized, placebo-controlled, double-masked clinical trial of etanercept for the treatment of uveitis associated with juvenile idiopathic arthritis. Arthritis Rheum. 2005:53(1):18-23.

61. Simonini G, Druce K, Cimaz R, Macfarlane GJ, Jones GT. Current evidence of anti-tumor necrosis factor a treatment efficacy in childhood chronic uveitis: a systematic review and meta-analysis approach of individual drugs. Arthritis Care Res. 2014;66(7):1073-84.

62. Simonini G, Taddio A, Cattalini M, Caputo R, De Libero C, Naviglio S, et al. Prevention of flare recurrences in childhood-refractory chronic uveitis: an open-label comparative study of adalimumab versus infliximab. Arthritis Care Res. 2011;63(4):612-8.

63. Dhingra N, Morgan J, Dick AD. Switching biologic agents for uveitis. Eye (Lond). 2009;23(9):1868-70.

64. Lerman MA, Lewen MD, Kempen JH, Mills MD. Uveitis reactivation in children treated with tumor necrosis factor alpha inhibitors. Am J Ophthalmol. 2015;160(1):193-200.e1.

65. Tynjälä P, Lindahl P, Honkanen V, Lahdenne P, Kotaniemi K. Infliximab and etanercept in the treatment of chronic uveitis associated with refractory juvenile idiopathic arthritis. Ann Rheum Dis. 2007;66(4):548-50.

66. Schmeling $H$, Horneff $G$. Etanercept and uveitis in patients with juvenile idiopathic arthritis. Rheumatology. 2005;44(8):1008-11.

67. Saurenmann RK, Levin AV, Feldman BM, Laxer RM, Schneider R, Silverman ED. Risk of new-onset uveitis in patients with juvenile idiopathic arthritis treated with anti-TNFalpha agents. J Pediatr. 2006;149(6):833-6.

68. Lim LL, Fraunfelder FW, Rosenbaum JT. Do tumor necrosis factor inhibitors cause uveitis? A registry-based study. Arthritis Rheum. 2007;56(10):3248-52 
69. Horneff G. Safety of biologic therapies for the treatment of juvenile idiopathic arthritis. Expert Opin Drug Saf. 2015;14(7):1111-26.

70. Foeldvari I, Becker I, Horneff G. Uveitis events during adalimumab, etanercept, and methotrexate therapy in juvenile idiopathic arthritis: data from the biologics in pediatric rheumatology registry. Arthritis Care Res. 2015:67(11):1529-35.

71. Tarkiainen M, Tynjala P, Vahasalo P, Lahdenne P. Occurrence of adverse events in patients with JIA receiving biologic agents: long-term follow-up in a real-life setting. Rheumatology. 2015;54(7):1170-6.

72. Angeles-Han S, Yeh S. Prevention and management of cataracts in children with juvenile idiopathic arthritis-associated uveitis. Curr Rheumatol Rep. 2012;14(2):142-9.

73. Quiñones K, Cervantes-Castañeda RA, Hynes AY, Daoud YJ, Foster CS. Outcomes of cataract surgery in children with chronic uveitis. J Cataract Refract Surg. 2009;35(4):725-31.

74. Grajewski RS, Zurek-Imhoff B, Roesel M, Heinz C, Heiligenhaus A. Favourable outcome after cataract surgery with $\mathrm{OL}$ implantation in uveitis associated with juvenile idiopathic arthritis. Acta Ophthalmol. 2012;90(7):657-62.

75. Freedman SF, Rodriguez-Rosa RE, Rojas MC, Enyedi LB. Goniotomy for glaucoma secondary to chronic childhood uveitis. Am J Ophthalmol. 2002;133(5):617-21.

76. Kafkala C, Hynes A, Choi J, Topalkara A, Foster CS. Ahmed valve implantation for uncontrolled pediatric uveitic glaucoma. J AAPOS. 2005;9(4):336-40.

77. Bohnsack BL, Freedman SF. Surgical outcomes in childhood uveitic glaucoma. Am J Ophthalmol. 2013;155(1):134-42.

78. Gregory AC, Kempen JH, Daniel E, Kaçmaz RO, Foster CS, Jabs DA, et al. Risk factors for loss of visual acuity among patients with uveitis associated with juvenile idiopathic arthritis: the systemic immunosuppressive therapy for eye diseases study. Ophthalmology. 2013;120(1):186-92.

79. Skarin A, Elborgh R, Edlund E, Bengtsson-Stigmar E. Long-term follow-up of patients with uveitis associated with juvenile idiopathic arthritis: a cohort study. Ocul Immunol Inflamm. 2009;17(2):104-8.

80. Kotaniemi K, Arkela-Kautiainen M, Haapasaari J, Leirisalo-Repo M. Uveitis in young adults with juvenile idiopathic arthritis: a clinical evaluation of 123 patients. Ann Rheum Dis. 2005:64(6):871-4.

81. Angeles-Han ST, Yeh S, Vogler LB. Updates on the risk markers and outcomes of severe juvenile idiopathic arthritis-associated uveitis. Int I Clin Rheumtol. 2013;8(1):109-121.

82. Chia A, Lee V, Graham EM, Edelsten C. Factors related to severe uveitis at diagnosis in children with juvenile idiopathic arthritis in a screening program. Am J Ophthalmol. 2003;135(6):757-62.

83. Edelsten C, Lee V, Bentley CR, Kanski JJ, Graham EM. An evaluation of baseline risk factors predicting severity in juvenile idiopathic arthritis associated uveitis and other chronic anterior uveitis in early childhood. Br J Ophthalmol. 2002;86(1):51-6.

84. Kalinina Ayuso V, Ten Cate HA, van der Does P, Rothova A, de Boer JH. Male gender and poor visual outcome in uveitis associated with juvenile idiopathic arthritis. Am J Ophthalmol. 2010;149(6):987-93.

85. Zannin ME, Buscain I, Vittadello F, Martini G, Alessio M, Orsoni JG, et al. Timing of uveitis onset in oligoarticular juvenile idiopathic arthritis (JIA) is the main predictor of severe course uveitis. Acta Ophthalmol. 2012;90(1):91-5.

86. Tappeiner C, Klotsche J, Schenck S, Niewerth M, Minden K, Heiligenhaus A. Temporal change in prevalence and complications of uveitis associated with juvenile idiopathic arthritis:data from a cross-sectional analysis of a prospective nationwide study. Clin Exp Rheumatol. 2015;33(6):936-44.

87. Kotaniemi K, Sihto-Kauppi K, Salomaa P, Säilä H, Ristolainen L, Kauppi M. The frequency and outcome of uveitis in patients with newly diagnosed juvenile idiopathic arthritis in two 4-year cohorts from 1990-1993 and 2000-2003. Clin Exp Rheumatol. 2014;32(1):143-7.

88. Tappeiner C, Schenck S, Niewerth M, Heiligenhaus A, Minden K, Klotsche J. Impact of anti-inflammatory treatment on the onset of uveitis in juvenile idiopathic arthritis: Longitudinal analysis from a nation-wide paediatric rheumatological database. Arthritis Care Res. 2015. doi:10.1002/acr.22649.

89. Lee RW, Nicholson LB, Sen HN, Chan CC, Wei L, Nussenblatt RB, et al. Autoimmune and autoinflammatory mechanisms in uveitis. Semin Immunopathol. 2014;36(5):581-94.

90. Ramanan AV, Dick AD, Benton D, Compeyrot-Lacassagne S, Dawoud D, Hardwick B, et al. A randomised controlled trial of the clinical effectiveness, safety and cost-effectiveness of adalimumab in combination with methotrexate for the treatment of juvenile idiopathic arthritis associated uveitis (SYCAMORE Trial). Trials. 2014;15:14.

91. Quartier P. Evaluation of the efficacy of adalimumab for the treatment of uveitis in juvenile idiopathic arthritis: randomized double-blind placebocontrolled trial. ClinicalTrials.gov [Internet]. Bethesda: National Library of Medicine (US). 2015. http://www.clinicaltrials.gov/show/NCT01385826. Accessed 4 Jan 2016.

92. A phase II trial of tocilizumab in anti-TNF refractory patients with JIA associated uveitis (APTITUDE study) [Internet]. BioMed Central. 2015 [cited 22 Dec 2015]. Available from: http://www.isrctn.com/ISRCTN95363507.

93. Suhler EB. An open-label trial to assess the efficacy and safety of Tocilizumab in the management of juvenile idiopathic arthritis associated vision-threatening uveitis that is refractory to other modes of systemic immunosuppression. ClinicalTrials.gov [Internet]. Bethesda: National Library of Medicine (US). 2015. http://www.clinicaltrials.gov/show/NCT01603355. Accessed 4 Jan 2016.

94. Suhler EB. An openlabel, phase II trial of Abatacept (Orencia) in the treatment of refractory non-infectious uveitis. ClinicalTrials.gov [Internet]. Bethesda: National Library of Medicine (US). 2015. http://www.clinicaltrials. gov/show/NCT01279954. Accessed 4 Jan 2016.

95. Chan ES, Cronstein BN. Methotrexate-how does it really work? Nat Rev Rheumatol. 2010;6(3):175-8.

96. Goebel JC, Roesel M, Heinz C, Michels H, Ganser G, Heiligenhaus A. Azathioprine as a treatment option for uveitis in patients with juvenile idiopathic arthritis. Br J Ophthalmol. 2011;95(2):209-13.

97. Doycheva D, Deuter C, Stuebiger N, Biester S, Zierhut M. Mycophenolate mofetil in the treatment of uveitis in children. Br J Ophthalmol. 2007:91(2):180-4.

98. Chang PY, Giuliari GP, Shaikh M, Thakuria P, Makhoul D, Foster CS. Mycophenolate mofetil monotherapy in the management of paediatric uveitis. Eye (Lond). 2011;25(4):427-35.

99. Sobrin L, Christen W, Foster CS. Mycophenolate mofetil after methotrexate failure or intolerance in the treatment of scleritis and uveitis. Ophthalmology. 2008;115(8):1416-21, 21.e1.

100. Tappeiner C, Roesel M, Heinz C, Michels H, Ganser G, Heiligenhaus A. Limited value of cyclosporine A for the treatment of patients with uveitis associated with juvenile idiopathic arthritis. Eye (Lond). 2009;23(5):1192-8.

101. Kilmartin DJ, Forrester JV, Dick AD. Cyclosporin A therapy in refractory non-infectious childhood uveitis. Br J Ophthalmol. 1998:82(7):737-42.

102. Hogan AC, McAvoy CE, Dick AD, Lee RW. Long-term efficacy and tolerance of tacrolimus for the treatment of uveitis. Ophthalmology. 2007;114(5):1000-6.

103. William M, Faez S, Papaliodis GN, Lobo AM. Golimumab for the treatment of refractory juvenile idiopathic arthritis-associated uveitis. J Ophthalmic Inflamm Infect. 2012;2(4):231-3.

104. Tappeiner C, Heinz C, Ganser G, Heiligenhaus A. Is tocilizumab an effective option for treatment of refractory uveitis associated with juvenile idiopathic arthritis? J Rheumatol. 2012;39(6):1294-5.

105. Tsang AC, Roth J, Gottlieb C. Tocilizumab for severe chronic anterior uveitis associated with juvenile idiopathic arthritis in a pediatric patient. Ocul Immunol Inflamm. 2014;22(2):155-7.

106. Zulian F, Balzarin M, Falcini F, Martini G, Alessio M, Cimaz R, et al. Abatacept for severe anti-tumor necrosis factor alpha refractory juvenile idiopathic arthritis-related uveitis. Arthritis Care Res. 2010;62(6):821-5.

107. Kenawy N, Cleary G, Mewar D, Beare N, Chandna A, Pearce I. Abatacept: a potential therapy in refractory cases of juvenile idiopathic arthritisassociated uveitis. Graefes Arch Clin Exp Ophthalmol. 2011;249(2):297-300.

108. Tappeiner C, Miserocchi E, Bodaghi B, Kotaniemi K, Mackensen F, Gerloni $\mathrm{V}$, et al. Abatacept in the treatment of severe, longstanding, and refractory uveitis associated with juvenile idiopathic arthritis. J Rheumatol. 2015:42(4):706-11.

109. Heiligenhaus A, Miserocchi E, Heinz C, Gerloni V, Kotaniemi K. Treatment of severe uveitis associated with juvenile idiopathic arthritis with anti-CD20 monoclonal antibody (rituximab). Rheumatology. 2011;50(8):1390-4

110. Miserocchi E, Pontikaki I, Modorati G, Bandello F, Meroni PL, Gerloni V. Rituximab for uveitis. Ophthalmology. 2011;118(1):223-4.

111. Miserocchi E, Modorati G, Berchicci L, Pontikaki I, Meroni P, Gerloni V. Long-term treatment with rituximab in severe juvenile idiopathic arthritis-associated uveitis. Br J Ophthalmol. 2015. doi:10.1136/bjophthalmol2015-306790. 